\title{
Assistência ao Homem na Estratégia Saúde da Família
}

\author{
Saryse Figueredo Castro Coelho ${ }^{1}$; Rosana Alves de Melo $^{2}$
}

Resumo: Apesar da ampliação da rede básica ter contribuído para melhor acessibilidade geográfica, evidenciouse desproporção na capacidade de atendimento à demanda de alguns gêneros, o que pode ser percebido em ações que são prioritariamente voltadas a saúde da criança, da mulher e do idoso, pouco favorecendo a saúde do homem adulto. O objetivo do presente estudo foi analisar quais os aspectos acerca da assistência ao homem na atenção primária à saúde têm sido analisados nas pesquisas realizados por profissionais de saúde. Trata-se de uma revisão integrativa da literatura em publicações sobre a assistência a saúde do homem, de 2009 a 2017. Os resultados demonstraram que as instâncias de saúde pouco incentivam a realização de campanhas e outras formas de disseminar informações aos homens e que, incluir a participação do homem nas ações de saúde ainda é um desafio para os serviços de saúde.

Palavras-chave: Saúde do homem, Políticas públicas, Saúde da Família.

\section{Assistance to the Man in the Family Health Strategy}

\begin{abstract}
Although the expansion of the basic network contributed to a better geographic accessibility, it was evidenced a disproportion in the capacity to meet the demand of some genera, which can be seen in actions that are primarily directed at the health of the child, the woman and the elderly, little favoring the health of the adult man. The objective of the present study was to analyze which aspects about the assistance to the man in the primary health care have been analyzed in the research done by health professionals. This is an integrative review of the literature in publications on health care for men, from 2009 to 2017 . The results showed that health organizations do not encourage campaigns and other forms of dissemination of information to men, which include the participation of men in health care is still a challenge for health services.
\end{abstract}

Keywords: Men's health, Public policies, Family health.

\section{Introdução}

A Atenção Primária à Saúde (APS) é porta de entrada para o sistema de saúde no Brasil, ela é fundamental para que o Sistema Único de Saúde (SUS) se consolide, tornando-se mais eficiente e oferecendo um serviço de qualidade aos usuários.

\footnotetext{
${ }^{1}$ Enfermeira formada pela Universidade Federal do Piauí; Especialista em Nefrologia pelo Instituto de Ensino Superior Múltiplo (IESM), Pósgraduanda em Gestão em Saúde pela Universidade Federal do Vale do Rio São Francisco (Univasf) e em Saúde da Família pela Universidade Federal do Piaui (UFPI). Atualmente coordena do curso Técnico em Enfermagem do CEEP - Lucinete Santana da Silva e atua como Enfermeira da Estratégia em Saúde da Família da Unidade Basica de Saúde na cidade de Acauã - PI. saryse_castro@hotmail.com

${ }^{2}$ Graduação em Enfermagem Bacharelado pela Universidade Estadual do Maranhão, Pós Graduação em Urgência e Emergência pelo Instituto Brasileiro de Pós Graduação e Extensão de Curitiba, Pós Graduação Didático Pedagógica para Educação em Enfermagem pela Universidade Federal de Pernambuco (2013), Mestre em Enfermagem pela Universidade Estadual de Feira de Santana/BA, Doutoranda em Inovações Terapêuticas pela Universidade Federal de Pernambuco. Professora assistente do colegiado de enfermagem da Universidade Federal do Vale do São Francisco - Campus Petrolina.
} 
Esses serviços são desenvolvidos por equipes multiprofissionais que atuam nas Unidades de Saúde da Família (USF). Nas quais, têm-se a responsabilidade de atender a população de forma integral, garantindo a universalização do acesso e a equidade da assistência prestada.

A política de saúde pública no Brasil desenvolvida ao longo dos anos 90 apresenta como principal característica, a ênfase na Atenção Básica $(A B)$ entre o conjunto de ações e serviços desenvolvidos pelo SUS. A ênfase na AB significa, antes de tudo, possibilitar que o conjunto da população seja atingido de forma integral por esse nível de atenção (MARQUES; MENDES, 2002).

Apesar da ampliação da rede básica ter contribuído para melhor acessibilidade geográfica, evidenciou-se desproporção na capacidade de atendimento à demanda de alguns gêneros, o que pode ser percebido em ações que são prioritariamente voltadas a saúde da criança, da mulher e do idoso, pouco favorecendo a saúde do homem adulto (SOUZA, 2008).

Incluir a participação do homem nas ações de saúde é um desafio para os serviços de saúde por diversos motivos. Estudo realizado por Gomes (2007) revelou que o imaginário de ser homem pode aprisionar o masculino em amarras culturais, dificultando a adoção de práticas de autocuidado, pois à medida que o homem é visto como viril, invulnerável e forte, procurar o serviço de saúde, numa perspectiva preventiva, poderia associá-lo à fraqueza, medo e insegurança.

Uma outra questão que reforça a ausência dos homens ao serviço de saúde seria o medo da descoberta de uma doença grave, assim, não saber pode ser considerado um fator de "proteção". Outra dificuldade para o acesso dos homens a esses serviços é a vergonha da exposição do seu corpo perante o profissional de saúde, particularmente a região anal, no caso da prevenção ao câncer de próstata.

Para minimizar tais fragilidades, o Ministério da Saúde (MS) em 2008 apresentou uma das prioridades do seu governo a "Política Nacional de Atenção Integral a Saúde do Homem" (PNAISH), que está alinhada com os princípios do SUS, a Política Nacional de Atenção Básica (PNAB) e com as estratégias de humanização em saúde, fortalecendo ações e serviços em redes e cuidados da saúde.

A PNAISH objetiva promover de forma significativa um avanço nas condições de saúde da população masculina, com ênfase na redução da morbimortalidade dessa população, através de ações que visem minimizar os fatores de riscos, melhorar o acesso e realizar a assistência de forma integral (BRASIL, 2008). 
Compreende-se, assim, que a criação dessa Política, embora retardatária, é crucial para que se inicie uma modificação na maneira de tratar e acolher os homens adultos nos serviços de saúde (SILVA, 2012). Essa preocupação vem aumentando, por considerar os altos níveis de morbimortalidade masculina e reconhecer que os referenciais de gênero podem contribuir para melhor entender os processos de adoecimento e morte dessa população que está, consideravelmente, vulnerável a acidentes e agravos decorrentes da violência, dependência de álcool, tabaco e outras drogas.

A situação da saúde masculina no Brasil é preocupante. De acordo com o Instituto Brasileiro de Geografia e Estatística (IBGE), a chance de um homem falecer aos 22 anos de idade é 4,5 maior que a de uma mulher. A expectativa de vida para a população brasileira é de aproximadamente 74 anos para ambos os sexos, no entanto os homens esperam viver 70,6 anos, ao passo que as mulheres esperam viver 77,7 anos (IBGE, 2011; 2012).

A inclusão das questões de gênero no processo saúde doença tem contribuído para os aspectos diferenciais entre a saúde do homem e da mulher e, logo, para as características distintas do padrão de morbimortalidade de cada sexo. A longevidade e os agravos à saúde passaram a ser compreendidos não pela distinção entre os sexos, mas também por comportamentos específicos, condições e estilo de vida (LUIZAGA, 2010).

Segundo Albano; Basílio; Neves (2010) fazem-se necessárias discussões mais amplas de todo o contexto no qual o homem está inserido, uma vez que o maior desafio das políticas públicas não é somente incluir o gênero masculino nos serviços de APS, mas também sensibilizá-los sobre a importância do cuidado e da inexistência de invulnerabilidade.

De acordo com estudos de Figueiredo (2005) a ideia dos serviços de saúde como um espaço feminimizado precisa ser transformada de modo a incluir as necessidades de saúde dos homens. Isto não significa basicamente apenas a mudança nos percentuais de trabalhadores homens e mulheres nesses serviços, tampouco a criação de serviços de saúde específicos para a população masculina. É evidente que um maior número de profissionais de saúde do sexo masculino nestes serviços, principalmente na equipe de enfermagem, contribuiria para melhor acesso dos homens nos postos de saúde.

No entanto, mais importante do que ter homens na assistência, é uma mudança da postura prática de todos os profissionais, sejam homens ou mulheres. É necessário que os profissionais de saúde tenham uma maior sensibilidade para as interações entre as concepções de gênero e as demandas trazidas pelos homens no uso do serviço (FIGUEREDO, 2005). 
O enfermeiro como profissional que atua na educação para a saúde, pode desenvolver um papel importante nesse contexto através de ações educativas de promoção e prevenção, explicando dúvidas e estimulando a população masculina a se cuidar, assim como é desenvolvido com crianças, mulheres e idosos através de programas e outras atividades (ALBANO; BASÍLIO; NEVES, 2010).

O objetivo do presente estudo foi analisar quais os aspectos acerca da assistência ao homem na atenção primária à saúde têm sido analisados nas pesquisas realizados por profissionais de saúde. Para isso foi necessário também: a) caracterizar a produção científica revisada quanto às características estruturais e metodológicas; b) verificar quais os fatores que contribuem para invisibilidade dos homens nos serviços de Atenção Primária à Saúde; e, c) identificar evidências científicas sobre as ações realizadas ou sugeridas para atrair os homens aos serviços de Atenção Básica.

\section{A saúde do homem no Brasil: aspectos legais e epidemiológicos}

A população brasileira em 2010 foi contabilizada em pouco mais de 190 milhões de habitantes, dos quais 49,0\% eram do sexo masculino. Desses, $56 \%$ estavam na faixa entre 20 e 59 anos. Esses dados revelam que, do total de homens brasileiros, um pouco mais da metade encontram-se na idade adulta, estando mais expostos às situações de morbidade, dentre elas, a violência, o alcoolismo e o tabagismo (BRASIL, 2008; SCHWARZI, 2012).

Historicamente, as políticas de saúde privilegiaram ações de saúde materno-infantil e de idosos e nesse contexto o homem permaneceu esquecido no que se refere a uma política de saúde voltada especificamente para ele. É fato que foram realizadas algumas campanhas que envolvessem esta população tais como alcoolismo, tabagismo e prevenção de DST, porém, essas ações isoladas não garantiam uma política pública específica aos homens.

Em consonância com os princípios e diretrizes do SUS, o MS em 2008 lançou uma política de saúde essencialmente voltada aos homens a "Política Nacional de Atenção Integral à Saúde do Homem" (PNAISH), que vem nortear ações de atenção integral à saúde do homem, visando estimular o autocuidado e, sobretudo, o reconhecimento de que a saúde é um direito social básico e de cidadania de todos os homens brasileiros e fortalecer ações e serviços em redes, privilegiando a ESF, evitando assim, a setorialização de serviços ou a segmentação de estruturas.

488 Id on Line Rev. Mult. Psic. V.12, N. 41, p. 485-508, 2018 - ISSN 1981-1179 
Desta forma, a PNAISH se estabeleceu mediante um recorte estratégico da população masculina na faixa etária de 25 a 59 anos. Esse grupo etário corresponde à parcela preponderante da força produtiva e, além do mais, exerce um significativo papel sociocultural e político. Isto não deve configurar uma restrição da população alvo, mas uma estratégia metodológica (BRASIL, 2008).

Essa política tem como objetivo principal promover a melhoria das condições de saúde da população masculina do Brasil, contribuindo, de modo efetivo, para a redução da morbidade e mortalidade dessa população, através do enfrentamento racional dos fatores de risco e mediante a ampliação do acesso, às ações e aos serviços de assistência integral à saúde (BRASIL, 2008).

De acordo com Leal; Figueiredo e Silva (2012) a implementação da PNAISH, envolve decisões de vários agentes em um determinado contexto: desde medidas tomadas pelos formuladores da política até às dos encarregados da implementação, sendo que nestes estão inclusos, além do gestor municipal de saúde, a equipe técnica local designada para atuar na saúde do homem e os profissionais que atuam nos serviços.

\section{A assistência do homem na APS}

Inserir os homens na atenção primária à saúde é um desafio às políticas públicas, pois estes não reconhecem a importância da promoção da saúde e prevenção de doenças como questões associadas ao homem. Muitas são as suposições e justificativas para a pouca presença masculina nos serviços de atenção primária à saúde (ALBANO; BASÍLIO; NEVES 2010).

Segundo Brasil (2010) a APS é a base dos sistemas nacionais de saúde por ser a melhor estratégia para produzir melhorias sustentáveis e maior equidade no estado de saúde da população. A APS pode ser definida como: um conjunto de valores, direito ao mais alto nível de saúde, solidariedade e equidade; um conjunto de princípios, responsabilidade governamental, sustentabilidade, intersetorialidade, participação social, entre outros e como um conjunto indissociável de elementos estruturantes do sistema de serviços de saúde: acesso de primeiro contato, integralidade, longitudinalidade, coordenação, orientação familiar e comunitária e competência cultural.

Em uma pesquisa realizada com profissionais de saúde, desenvolvida por Knauth; Couto; Figueiredo (2012), revela que a clientela dos serviços de saúde continua, apesar da 
tímida implantação da PNAISH, a ser majoritariamente feminina e infantil. Segundo as estimativas que apresentam, a população masculina representa no máximo entre $30 \%$ e $40 \%$ da demanda. Reconhecem, contudo, que esta situação está se modificando rapidamente, visto que na atualidade o número de homens já é superior ao observado há alguns anos.

Os homens que frequentam os serviços de saúde são divididos em duas categorias: trabalhadores e idosos. O primeiro grupo, minoritário, é formado por homens entre 30 e 50 anos e se caracteriza por estar exercendo atividade remunerada, ser trabalhador e ter pouco tempo disponível para ir ao serviço de saúde. Já o segundo grupo, que contempla a maior parte dos homens, frequenta a unidade de saúde em razão de alguma doença crônica para consulta, busca de receita ou medicamento (KNAUTH; COUTO; FIGUEIREDO, 2012).

A demanda dos homens nos serviços limita-se a ações de cunho curativo a partir de alguma doença já instalada como diabetes e hipertensão. Diferentemente de crianças, mulheres e idosos que comparecem aos serviços de saúde de forma mais preventiva utilizando os serviços de vacinação, puericultura, pré-natal dentre outros. Essa resistência do homem em se cuidar não está associada apenas às condições sociais ou a época, e sim a uma cultura em que os homens são educados como seres fortes e resistentes quando comparados ao gênero feminino (ALBANO; BASÍLIO; NEVES 2010).

\section{O profissional de saúde frente ao Programa de Saúde do Homem}

O homem apresenta um conjunto de características próprias que são mantidas desde o período primitivo. A inclusão dos homens em ações de saúde é desafiadora, pois estes não reconhecem a importância da promoção da saúde e a valorização do corpo. O enfermeiro, além de ser um profissional da saúde, atua como um educador, esclarecendo dúvidas e incentivando a população masculina a cuidados próprios (SILVA et al., 2013).

Estudo realizado por Salimena (2013) revela que os homens não têm sido atendidos em suas necessidades, ou seja, o princípio da integralidade que assegura o atendimento do sujeito em toda a sua dimensão não se faz presente na assistência prestada a esses homens.

A criação de vínculos afetivos e efetivos entre o usuário e o profissional de saúde também representa uma das necessidades a serem atendidas, uma vez que a resignificação da vida diante da doença por parte do paciente, depende em parte do profissional de saúde e, a 
ausência desses vínculos e a falta de relação de confiança com o sistema de saúde, prejudica, consequentemente, o processo de tratamento do paciente (SALIMENA, 2013).

Aumentar a visibilidade das demandas da população masculina, a partir de ações mais efetivas constitui-se em um desafio para a saúde coletiva, uma vez que as ações de prevenção e promoção à saúde dos homens estão vinculadas às especificidades de cada local e às características da equipe interdisciplinar. Para que ocorram mudanças benéficas na $\mathrm{AB}$, as ações de saúde devem contribuir significativamente para a compreensão da realidade singular masculina nos seus diversos contextos socioculturais e político-econômicos; outro é o respeito aos diferentes níveis de desenvolvimento e organização dos sistemas locais de saúde e tipos de gestão (BRASIL, 2008; SCHEUER; BONFADA, 2008).

Segundo Scheuer (2008) faz-se necessário elaborar estratégias que possam impulsionar uma prática cotidiana mais eficaz por meio de ações que visem a uma melhor percepção e acolhimento das demandas de saúde dos indivíduos do gênero masculino nas UBS.

Logo, as ações do profissional enfermeiro na PNAISH devem estar pautadas nos objetivos e na nova visão de atendimento ao novo paradigma emergente que é prestar cuidados ao homem a partir da atenção básica, num modelo de promoção e prevenção a este grupo. São objetivos da PNAISH promover melhores condições de saúde à população masculina do Brasil.

\section{Metodologia}

\section{Tipo de Estudo}

Este estudo será revisão integrativa da literatura que é um dos métodos de pesquisa utilizados na Prática Baseada em Evidências (PBE), ou seja, seus resultados podem ser utilizados na prática clínica, sendo uma síntese do conhecimento gerado sobre determinado assunto e uma maneira de se identificar as lacunas que ainda precisam ser preenchidas com novas pesquisas (LIMA, 2013).

Para a elaboração desse método, serão desenvolvidas as seguintes etapas: estabelecimento da questão norteadora da pesquisa, busca na literatura, coleta de dados, análise crítica dos estudos incluídos, interpretação e síntese dos resultados e apresentação da revisão. 


\section{Ambiente da Investigação}

A seleção dos estudos será a partir da busca nas Bases de Dados: Base de Dados em Enfermagem (Bdenf) e no Centro Latino-Americano e do Caribe de Informação em Ciências da Saúde (Lilacs) das publicações de 2009 a 2017. Essas bases de dados bibliográficos proporcionam acesso aos estudos primários e às revisões sistemáticas relacionadas à prática e à em saúde.

A BDENF é uma fonte de informação composta por referências bibliográficas da literatura técnica - cientifica brasileira em Enfermagem. Contém artigos das revistas mais conceituadas da área de Enfermagem, e outros documentos tais como: teses, livros, capítulos de livros, anais de congressos ou conferências, relatórios técnico-científicos e publicações governamentais.

O LILACS é um produto cooperativo da Biblioteca Virtual de Saúde (BVS) relativo às ciências da saúde, publicada nos países da América Latina e Caribe, a partir de 1982. Possui mais de 600.000 registros bibliográficos de artigos publicados em cerca de 1.500 periódicos em ciência da saúde. O LILACS também indexa outros tipos de literatura científica e técnica como teses, monografias, livros e capítulos de livros, trabalhos apresentados em congressos ou conferências, relatórios, publicações governamentais e de organismos internacionais regionais.

\section{Coleta de dados}

A investigação ocorreu no mês de outubro de 2017. Os critérios de inclusão serão: estudos que abordassem a temática saúde do homem e/ou atenção primária, estar disponível eletronicamente na íntegra e estudos publicados em português entre o período de 2009 e 2017.

\section{Análise dos dados}

Os estudos foram separados de acordo com as seguintes categorias: aspectos estruturais e metodológicos das produções e evidências quanto à assistência à saúde do homem no nível primário de atenção à saúde. 


\section{Resultados e Discussão}

Inicialmente, serão apresentados e analisados os resultados da revisão de modo a caracterizar os estudos selecionados e, posteriormente, será feita uma exposição, entremeada por discussão, dos elementos integrantes acerca da assistência ao homem na APS.

$\mathrm{Na}$ Tabela 1, estão relacionados os descritores, total de artigos encontrados, préselecionados, excluídos e incluídos a partir das análises realizadas.

Tabela 1 - Distribuição dos achados segundo as bases de dados eletrônicas. Picos-PI, ago., 2013.

\begin{tabular}{lccc}
\hline Base de dados & BDENF & LILACS & TOTAL \\
\hline Encontrados & 9 & 44 & 53 \\
\hline Excluídos por repetição & 2 & 2 & 4 \\
\hline $\begin{array}{l}\text { Excluídos por não responderem à } \\
\text { questão norteadora }\end{array}$ & 6 & 36 & 42 \\
\hline Incluídos para análise na íntegra & 1 & 6 & 7 \\
\hline
\end{tabular}

Fonte: Pesquisa dos autores

Usando os descritores, Saúde do Homem e Atenção Primária na base de dados BDENF, foram encontrados nove artigos. Na Lilacs utilizando o descritor Saúde do Homem, pôde-se obter um total de 44 publicações.

Um fator que contribuiu para a exclusão de muitos artigos foi o ano de publicação, que de acordo com critério de inclusão do estudo foi delimitado um período de cinco anos (2009 2013), o que mostra a escassez de trabalhos atuais publicados em português. Vários estudos foram pré-selecionados por título, mas após a leitura do resumo verificou-se que os mesmos não se enquadravam nos objetivos do presente estudo. E ainda, quatro trabalhos publicados se repetiram entre as bases, o que também levou à exclusão dos mesmos. Portanto, sete artigos constituíram a amostra definitiva para esta revisão (Tabela 1).

O quadro 1 relaciona os estudos incluídos e as informações adicionais sobre a publicação. 


\section{Características estruturais dos estudos selecionados}

Quadro 1 - Aspectos estruturais das produções científicas encontradas. Picos - PI, ago. 2013.

\begin{tabular}{|c|c|c|c|c|c|c|}
\hline $\begin{array}{c}\text { Código } \\
\text { do } \\
\text { Estudo }\end{array}$ & Periódico & Qualis & Título do Artigo & $\begin{array}{c}\text { Formação Profissional } \\
\text { dos Autores }\end{array}$ & Ano & País \\
\hline A1 & $\begin{array}{l}\text { Rev. Rene. } \\
\text { Fortaleza }\end{array}$ & B2 & $\begin{array}{l}\text { Olhar masculino acerca } \\
\text { do atendimento na } \\
\text { estratégia saúde da } \\
\text { família }\end{array}$ & - $\quad$ Efermeiro & 2010 & Brasil \\
\hline A2 & $\begin{array}{l}\text { Interface - } \\
\text { Comunic., } \\
\text { Saude, Educ. }\end{array}$ & B2 & $\begin{array}{l}\text { Questões de sexualidade } \\
\text { masculina } \\
\text { na atenção primária à } \\
\text { saúde: gênero e } \\
\text { medicalização }\end{array}$ & $\begin{array}{ll}\text { - } & \text { Médico } \\
\text { - } & \text { Psicólogo }\end{array}$ & 2011 & Brasil \\
\hline A3 & $\begin{array}{l}\text { Ciência \& } \\
\text { Saúde } \\
\text { Coletiva }\end{array}$ & B2 & $\begin{array}{l}\text { Os homens não vêm! } \\
\text { Ausência e/ou } \\
\text { invisibilidade masculina } \\
\text { na atenção primária }\end{array}$ & $\begin{array}{ll}\text { - } & \text { Socióloga } \\
\text { - } & \text { Assistente Social } \\
\text { - } & \text { Pedagoga } \\
\text { - } & \text { Médica }\end{array}$ & 2011 & Brasil \\
\hline A4 & $\begin{array}{l}\text { Physis } \\
\text { Revista de } \\
\text { Saúde } \\
\text { Coletiva }\end{array}$ & B1 & $\begin{array}{l}\text { O atendimento à saúde de } \\
\text { homens: estudo } \\
\text { qualitativo em quatro } \\
\text { estados brasileiros }\end{array}$ & $\begin{array}{ll}\text { - } & \text { Sociólogo } \\
\text { - } & \text { Médica }\end{array}$ & 2011 & Brasil \\
\hline A5 & $\begin{array}{l}\text { Ciência \& } \\
\text { Saúde } \\
\text { Coletiva }\end{array}$ & B2 & $\begin{array}{l}\text { Concepções de gênero de } \\
\text { homens usuários e } \\
\text { profissionais de saúde de } \\
\text { serviços de atenção } \\
\text { primária e os possíveis } \\
\text { impactos } \\
\text { na saúde da população } \\
\text { masculina, São Paulo, } \\
\text { Brasil }\end{array}$ & $\begin{array}{ll}\text { - } & \text { Médico } \\
\text { - } & \text { Psicóloga }\end{array}$ & 2011 & Brasil \\
\hline A6 & $\begin{array}{l}\text { Interface - } \\
\text { Comunic., } \\
\text { Saude, Educ. }\end{array}$ & B2 & $\begin{array}{l}\text { O homem na atenção } \\
\text { primária à saúde: } \\
\text { discutindo } \\
\text { (in)visibilidade a partir } \\
\text { da perspectiva de gênero }\end{array}$ & $\begin{array}{ll}\text { - } & \text { Socióloga } \\
\text { - } & \text { Médico }\end{array}$ & 2010 & Brasil \\
\hline A7 & $\begin{array}{l}\text { Cad. Saúde } \\
\text { Pública }\end{array}$ & A2 & $\begin{array}{l}\text { Necessidades de saúde e } \\
\text { masculinidades: atenção } \\
\text { primária no cuidado aos } \\
\text { homens }\end{array}$ & $\begin{array}{ll}\text { - } & \text { Socióloga } \\
\text { - } & \text { Médico }\end{array}$ & 2010 & Brasil \\
\hline
\end{tabular}

Fonte: Pesquisa dos autores

Observa-se que as fontes de publicação são diversificadas e que todas são de origem brasileira, trazendo como foco a assistência ao homem na atenção primária a saúde. O número 
de publicações que abordam essa temática, dentro dos critérios de inclusão desse trabalho, é considerado pequeno. Visto que, a saúde do homem entrou em pauta recentemente no Brasil com a implantação da PNAISH.

Nota-se ainda, a crescente preocupação em estudar as relações entre masculinidade e cuidado em saúde com base na perspectiva de gênero, focalizando as dificuldades dos homens na busca por assistência de saúde e as formas como os serviços lidam com as demandas específicas dos homens, o que pode ampliar as dificuldades (COUTO et al., 2010).

Quanto ao período de publicação, três trabalho eram referentes ao ano de 2010 e quatro ao ano de 2011. Os referentes estudos mencionam a concepção dos usuários e profissionais de saúde quanto à invisibilidade dos homens na UBS e o que pode ser feito para atrair essa clientela.

Segundo Schraiber (2010), em A7, mesmo o homem estando inserido em contextos sociais diversos, a sua percepção sobre a saúde se aproxima: embora não neguem que têm necessidades de assistência à saúde, destacam várias dificuldades em procurar os serviços. Afirmam que os homens preferem retardar ao máximo a busca por assistência e só o fazem quando não conseguem mais lidar sozinhos com seus sintomas.

Quanto à formação dos profissionais, 16 autores são graduados em medicina, $12 \mathrm{em}$ sociologia, três em enfermagem e os demais correspondiam às áreas de psicologia, pedagogia e assistência social. Apenas no estudo A1 a enfermagem se fez presente, o que evidencia que os enfermeiros pesquisam pouco sobre a assistência ao homem no nível primário de atenção a saúde.

Na pesquisa A6 desenvolvida por Couto et al. (2010) a ênfase da APS está voltada para problemas de saúde considerados mais simples e corriqueiros e, também, à articulação cura e prevenção, tornando o atendimento diverso daquele mais episódico e direto sobre as doenças. A falta de atenção ao público masculino reflete uma desqualificação dos homens para esta perspectiva assistencial. Nesse sentido, não se valoriza e nem se vê como adequado ou pertinente que os homens sejam alvo de intervenções na lógica organizacional dos serviços, quando se trata da APS, o que remete para sua desqualificação no campo das políticas públicas de saúde, aspecto que consideramos como uma forma de invisibilidade dessa população.

Estudo realizado por Alvarenga (2012) revela que os homens não somente merecem como precisam ser assistidos pelos programas de saúde que buscam a redução dos índices de morbimortalidade e da exposição destes aos fatores de riscos, fortalecendo a manutenção da estrutura familiar, e também, por eles constituírem uma parcela significativa da população, pois, 
a faixa etária masculina contemplada pela política de saúde do homem está contida na força produtiva e política do país.

No quadro a seguir serão apresentadas as características metodológicas dos estudos selecionados.

\section{Características metodológicas dos estudos selecionados}

\begin{tabular}{|c|c|c|c|c|c|}
\hline $\begin{array}{l}\text { Código } \\
\text { dos } \\
\text { Estudos }\end{array}$ & Objetivo & $\begin{array}{c}\text { Tamanho } \\
\text { da } \\
\text { Amostra } \\
\end{array}$ & $\begin{array}{c}\text { Coleta de } \\
\text { Dados }\end{array}$ & $\begin{array}{l}\text { Tipos de } \\
\text { Estudo }\end{array}$ & $\begin{array}{c}\text { Tratamento } \\
\text { dos Dados }\end{array}$ \\
\hline A1 & $\begin{array}{l}\text { Identificar a opinião de } \\
\text { homens sobre o } \\
\text { atendimento recebido } \\
\text { na Estratégia Saúde da } \\
\text { Família. }\end{array}$ & 11 & $\begin{array}{c}\text { Entrevista } \\
\text { semiestruturada. }\end{array}$ & $\begin{array}{c}\text { Exploratório, } \\
\text { descritivo e } \\
\text { qualitativo. }\end{array}$ & $\begin{array}{c}\text { Análise de } \\
\text { Conteúdo, } \\
\text { segundo Bardin. }\end{array}$ \\
\hline A2 & $\begin{array}{l}\text { Compreender como a } \\
\text { sexualidade dos } \\
\text { homens usuários dos } \\
\text { serviços se apresenta } \\
\text { no contexto da } \\
\text { assistência, e como as } \\
\text { demandas que se } \\
\text { configuram nesse } \\
\text { âmbito são abordadas. }\end{array}$ & 57 & $\begin{array}{c}\text { Análise diária de } \\
\text { campo produzida } \\
\text { em observações } \\
\text { etnográficas e } \\
\text { depoimentos } \\
\text { colhidos em } \\
\text { entrevistas. }\end{array}$ & $\begin{array}{l}\text { Multicêntrico } \\
\text { e qualitativo. }\end{array}$ & $\begin{array}{l}\text { Análise e } \\
\text { interpretação } \\
\text { etnográficas. }\end{array}$ \\
\hline $\mathbf{A 3}$ & $\begin{array}{l}\text { Analisar como se dá a } \\
\text { relação homens- } \\
\text { assistência à saúde em } \\
\text { quatro estados (Rio } \\
\text { Grande do Norte, } \\
\text { Pernambuco, Rio de } \\
\text { Janeiro e São Paulo), } \\
\text { financiada pelo } \\
\text { Conselho Nacional de } \\
\text { Desenvolvimento } \\
\text { Científico e } \\
\text { Tecnológico }(\mathrm{CNPq}) \text {. }\end{array}$ & 20 & $\begin{array}{c}\text { Entrevista } \\
\text { semiestruturada }\end{array}$ & $\begin{array}{l}\text { Multicêntrico } \\
\text { e qualitativo. }\end{array}$ & $\begin{array}{c}\text { Método de } \\
\text { interpretação de } \\
\text { sentidos, } \\
\text { baseando-se em } \\
\text { princípios } \\
\text { hermenêutico- } \\
\text { dialéticos. }\end{array}$ \\
\hline A4 & $\begin{array}{l}\text { Analisar os sentidos } \\
\text { atribuídos por usuários } \\
\text { homens ao } \\
\text { atendimento que lhes é } \\
\text { prestado no âmbito da } \\
\text { atenção básica à saúde, } \\
\text { buscando subsidiar a } \\
\text { construção de } \\
\text { indicadores } \\
\text { qualitativos de } \\
\text { satisfação em relação } \\
\text { ao uso desses serviços } \\
\text { por usuários } \\
\text { masculinos. }\end{array}$ & 201 & $\begin{array}{c}\text { Entrevista } \\
\text { semiestruturada. }\end{array}$ & $\begin{array}{c}\text { Exploratório, } \\
\text { descritivo e } \\
\text { qualitativo }\end{array}$ & $\begin{array}{l}\text { Método de } \\
\text { interpretação de } \\
\text { sentidos, } \\
\text { baseando-se em } \\
\text { princípios } \\
\text { hermenêutico- } \\
\text { dialéticos. }\end{array}$ \\
\hline
\end{tabular}




\begin{tabular}{|c|c|c|c|c|c|}
\hline A5 & $\begin{array}{l}\text { Investigou como se dão } \\
\text { as representações e } \\
\text { interações entre } \\
\text { usuários (homens) e } \\
\text { profissionais de saúde } \\
\text { de serviços de atenção } \\
\text { primária. }\end{array}$ & 53 & $\begin{array}{c}\text { Observação direta } \\
\text { dos diferentes } \\
\text { contextos e } \\
\text { entrevista } \\
\text { semiestruturada. }\end{array}$ & $\begin{array}{c}\text { Exploratório, } \\
\text { descritivo e } \\
\text { qualitativo }\end{array}$ & $\begin{array}{l}\text { Técnica de } \\
\text { análise temática } \\
\text { de conteúdo }\end{array}$ \\
\hline A6 & $\begin{array}{l}\text { Compreender a } \\
\text { (in)visibilidade dos } \\
\text { homens no cotidiano } \\
\text { da assistência a partir } \\
\text { da perspectiva de } \\
\text { gênero, que discute os } \\
\text { mecanismos } \\
\text { promotores de } \\
\text { desigualdades } \\
\text { presentes no trabalho } \\
\text { em saúde. }\end{array}$ & 8 & $\begin{array}{l}\text { Analise diários de } \\
\text { campo produzidos } \\
\text { em observações } \\
\text { etnográficas. }\end{array}$ & $\begin{array}{c}\text { Multicêntrico } \\
\text { e qualitativo }\end{array}$ & $\begin{array}{c}\text { Análise e } \\
\text { interpretação } \\
\text { etnográficas } \\
\text { segundo os } \\
\text { princípios do } \\
\text { método de } \\
\text { interpretação de } \\
\text { sentidos. }\end{array}$ \\
\hline A7 & $\begin{array}{l}\text { Estudam-se relações } \\
\text { entre masculinidades e } \\
\text { cuidado em saúde, } \\
\text { abordando o } \\
\text { reconhecimento de } \\
\text { necessidades por } \\
\text { homens usuários de } \\
\text { atenção primária e } \\
\text { respostas dos serviços. }\end{array}$ & 254 & $\begin{array}{l}\text { Analise diários de } \\
\text { campo produzido } \\
\text { em observações } \\
\text { etnográficas e } \\
\text { entrevista semi } \\
\text { estruturada. }\end{array}$ & $\begin{array}{l}\text { Multicêntrico } \\
\text { e qualitativo }\end{array}$ & $\begin{array}{c}\text { A análise } \\
\text { realizou-se a } \\
\text { partir de uma } \\
\text { adaptação da } \\
\text { proposta } \\
\text { hermenêutico- } \\
\text { dialética de } \\
\text { Minayo. }\end{array}$ \\
\hline
\end{tabular}

Fonte: Pesquisa dos autores

Quanto à metodologia utilizada para produção desses artigos, três estudos eram do tipo descritivo-exploratório e quatro pesquisas multicêntricas, sendo sete estudos de abordagem qualitativas. As técnicas de coleta de dados utilizadas foram: análise diária de campo que permite o pesquisador analisar, em tempo real, atitudes, fatos e fenômenos percebidos no campo de pesquisa e entrevista semiestruturada que é a utilização de um roteiro previamente elaborado contendo perguntas de caráter objetivo e subjetivo.

Com relação aos objetivos dos estudos analisados, cinco deles tinham como objetivo principal investigar a relação entre usuários homens e os serviços de atenção primária dentro de aspectos específicos de cada estudo. Um estudo objetivou compreender a ausência dos homens nas UBS e outra pesquisa buscou compreender a relação entre masculinidade e cuidados com a saúde.

Em seguida, no quadro 3, serão apresentadas as principais dificuldade de acesso aos serviços de atenção primária, bem como medidas que podem ser utilizadas para viabilizar o acesso dos usuários homens. 
Quadro 3 - Evidências quanto às dificuldades de acesso dos homens às UBS e as propostas de intervenção. Picos - PI, ago., 2013.

\begin{tabular}{|c|c|c|c|}
\hline $\begin{array}{l}\text { Código } \\
\text { dos } \\
\text { Estudos }\end{array}$ & $\begin{array}{l}\text { Caracterização do } \\
\text { Estudo e População }\end{array}$ & Evidências publicadas & $\begin{array}{c}\text { Propostas de intervenção realizadas e sugeridas pelos } \\
\text { estudos }\end{array}$ \\
\hline A1 & $\begin{array}{l}\text { Local (estado): RN } \\
\text { Instituição: UBS e SMS } \\
\text { População: homens } \\
\text { Faixa etária: } 20 \text { a } 29 \text { anos }\end{array}$ & $\begin{array}{l}\text { - Filas extensas; } \\
\text { - O horário de funcionamento das instituições de } \\
\text { saúde é incompatível com a jornada de trabalho; } \\
\text { Poucos profissionais atuando na ESF e ausência de } \\
\text { especialidades médicas; } \\
\text { - Demora em conseguir consulta médica e exames } \\
\text { laboratoriais. }\end{array}$ & $\begin{array}{l}\text { - Visita domiciliária; } \\
\text { - } \quad \text { Estruturar um serviço humanizado e que esteja pautado na } \\
\text { - Otimunizaçãão entre profissional-usuário; } \\
\text { - } \quad \text { Reestruturar as UBS no sentido de estender o seu horário } \\
\text { de atendimento para o período noturno. }\end{array}$ \\
\hline A2 & $\begin{array}{l}\text { Local (estado): PE, RJ, } \\
\text { RN, SP } \\
\text { Instituição: UBS } \\
\text { População: homens } \\
\text { Faixa etária: } 16 \text { a } 60 \\
\end{array}$ & $\begin{array}{l}\text { Número insuficiente de atendimentos a pacientes } \\
\text { portadores de IST; } \\
\text { Preconceito; }\end{array}$ & $\begin{array}{l}\text { - Abordagem de problemas relativos à ereção nas UBS, } \\
\text { IST's e câncer de próstata. }\end{array}$ \\
\hline A3 & $\begin{array}{l}\text { Local (estado): PE, RJ, } \\
\text { RN, SP } \\
\text { Instituição: UBS } \\
\text { População: Profissionais } \\
\text { de Saúde } \\
\text { Faixa etária: não } \\
\text { identificada }\end{array}$ & $\begin{array}{l}\text { - Filas extensas; } \\
\text { - O horário de funcionamento das instituições de } \\
\text { - } \quad \text { Paúde é incompatível com a jornada de trabalho; } \\
\text { - } \quad \text { Ausência da infra-estrutura material (horários, } \\
\text { remuneração, inputs para propiciar a } \\
\text { formação/trabalho interdisciplinar e contínuo } \\
\text { aprimoramento dos profissionais) } \\
\text { - Inexistência de programas voltados para a saúde } \\
\text { - } \quad \text { Ausculina; } \\
\text { - Vergoncia de uma cultura no autocuidado; } \\
\text { - Preconceito e medo. }\end{array}$ & $\begin{array}{l}\text { - Adoção de estratégias voltadas tanto para a ampliação da } \\
\text { oferta de ações como para a sensibilização dos homens } \\
\text { para cuidarem de sua saúde. }\end{array}$ \\
\hline A4 & $\begin{array}{c}\text { Local (estado): PE, RJ, } \\
\text { RN, SP } \\
\text { Instituição: UBS } \\
\text { População: Homens } \\
\text { Faixa etária: } 25 \text { a } 65 \text { anos }\end{array}$ & $\begin{array}{l}\text { - } \quad \text { Filas extensas; } \\
\text { - } \quad \text { Demora no atendimento; } \\
\text { - } \quad \text { Falta de medicamentos. }\end{array}$ & $\begin{array}{l}\text { - } \quad \text { Maior oferta de atendimento; } \\
\text { - } \quad \text { Atenção por parte do profissional; } \\
\text { - } \quad \text { Facilidade na marcação de consultas; } \\
\text { - } \quad \text { Remuneração dos profissionais de saúde para que } \\
\quad \text { pudessem oferecer uma melhor assistência; }\end{array}$ \\
\hline
\end{tabular}




\begin{tabular}{|c|c|c|c|}
\hline & & & $\begin{array}{l}\text { - Campanha publicitária voltada à Saúde do Homem; } \\
\text { Assistência especializada, tais como psicológica, } \\
\text { sexológica e urológica. }\end{array}$ \\
\hline A5 & $\begin{array}{l}\text { Local (estado): SP } \\
\text { Instituição: UBS } \\
\text { População: Homens e } \\
\text { profissionais de saúde } \\
\text { Faixa etária: Homens de } \\
18 \text { de } 60 \text { anos } \\
\end{array}$ & - Preconceito. & $\begin{array}{l}\text { Temáticas como trabalho e sexualidade, por exemplo, } \\
\text { devem ser contempladas nas discussões de prevenção e } \\
\text { promoção da saúde. }\end{array}$ \\
\hline A6 & $\begin{array}{l}\text { Local (estado): PE, RJ, } \\
\text { RN, SP } \\
\text { Instituição:UBS } \\
\text { População: Profissionais } \\
\text { de Saúde } \\
\text { Faixa etária: não } \\
\text { identificado } \\
\end{array}$ & $\begin{array}{l}\text { Os ambientes não favorecem a presença e } \\
\text { permanência dos homens, já que todos se } \\
\text { apresentam como espaços demarcadamente } \\
\text { femininos; }\end{array}$ & $\begin{array}{l}\text { - Disponibilizar atendimento em turnos de } 24 \text { horas, aos } \\
\text { sábados ou num terceiro turno à noite; } \\
\text { - Qualificação dos profissionais de saúde para o } \\
\text { atendimento da população masculina; } \\
\text { - Criação de espaço para os usuários do sexo masculino e } \\
\text { criação de um grupo específico para discussão da Saúde } \\
\text { do Homem. }\end{array}$ \\
\hline A7 & $\begin{array}{l}\text { Local (estado): PE, RJ, } \\
\text { RN, SP } \\
\text { Instituição: UBS } \\
\text { População: Usuários } \\
\text { homens e profissionais de } \\
\text { saúde } \\
\text { Faixa etária: Homens de } \\
15 \text { a } 65 \text { anos }\end{array}$ & $\begin{array}{l}\text { - Alguns homens têm o pensamento mágico de } \\
\text { sentirem-se invulneráveis e imunes ao } \\
\text { adoecimento; } \\
\text { - Falta de tempo para procurarem os serviços e } \\
\text { receios da perda do emprego; } \\
\text { - Dificuldade de acesso e o funcionamento dos } \\
\text { serviços; }\end{array}$ & - $\mathrm{O}$ atendimento deve ser rápido e pontual; \\
\hline
\end{tabular}


Mesmo os estudos tendo sido realizados em vários estados brasileiros, com situações socioeconômicas e culturais diferentes, os resultados em geral são bem parecidos. Eles indicam vários fatores que inibem os homens a procurarem a atenção primária, como: filas extensas, o horário de funcionamento da unidade, a demora em marcação de exames e/ou consultas, a femininização dos ambientes, ausência de programas específicos aos homens, falta de profissionais especialistas e de medicamentos, medo e preconceito.

Quanto às propostas de intervenção, cinco estudos relevam a importância de investir em promoção e prevenção. Silva (2013), em seu estudo, mostra que é necessário que os profissionais de saúde, em relação à saúde do homem, adotem formas diferentes de pensar, rompam crenças e valores para incorporar novos conceitos pertencentes a sua saúde, adequando as ações de prevenção, promoção, proteção e recuperação aos períodos contrários aos do trabalho deles.

Com relação à amostra, três estudos trazem como público alvo os homens; em dois trabalhos os profissionais de saúde e em dois trabalhos os homens e os profissionais de saúde.

No que diz respeito à faixa etária da população estudada, teve uma variação com a mínima de 15 anos (A7) e máxima de 65 anos (A4 e A7). Em dois estudos (A3 e A6) não foram identificadas as idades dos homens, pois tratam-se de pesquisas realizadas exclusivamente com profissionais de saúde.

Quanto à instituição de realização dos estudos, todos foram realizados em UBS. No que diz respeito ao local, um estudo foi realizado na região nordeste, um na região sudeste e cinco por se tratar de pesquisa multicêntrica, foram realizados nas regiões nordeste e sudeste.

\section{Motivos para invisibilidade dos homens nos serviços de Atenção Básica à Saúde}

Três estudos (A1, A3 e A4) mencionam as filas extensas como um dos principais problemas de acessibilidade.

No estudo realizado por Brito (2010) em A1, exibe a insatisfação dos usuários quanto à perda de tempo em filas de esperas. Para eles, independentemente do sexo, esse fato é 
considerado um dos pontos negativos das instituições de baixa complexidade juntamente com a demora de conseguir consultas médicas e exames laboratoriais.

Em A3, estudo desenvolvido por Gomes (2011a), as dificuldades com o funcionamento em rede pouco resolutiva contribuem para a evasão dos usuários do sistema. A demanda cresce, mas o número de profissionais não, gerando uma sobrecarga nas unidades onde determinados especialistas são encontrados.

Gomes (2011b) em A4 ressalta que as reclamações sobre a demora em ser atendido apontam para problemas que necessariamente não são de responsabilidade direta dos profissionais que prestam os cuidados nos serviços, como dificuldades de se equacionar a oferta dos serviços com a demanda.

Ademais, os estudos A1 e A3 fazem referência ao horário de funcionamento das instituições de saúde que é incompatível com a jornada de trabalho dos indivíduos inseridos no mercado formal ou informal, desestimulando os homens à procura desses serviços. O trabalho A1 justifica esse fato pelo receio que os homens têm em serem prejudicados por ausentarem-se de seus trabalhos para buscar auxílio médico. Esse prejuízo estaria ligado à possibilidade de perda do emprego, o que impossibilitaria os homens de desempenharem suas funções enquanto provedores de suas famílias.

Acredita-se que, de acordo com A1, reestruturar as UBS no sentido de estender o seu horário de atendimento para o período noturno oportunizaria a busca por assistência tanto daqueles inseridos no mercado formal de trabalho, como aos trabalhadores autônomos que, muitas vezes, obtém renda pela quantidade de horas trabalhadas.

Outro fator que dificulta a acessibilidade dos homens é a carência de profissionais trabalhando na atenção básica e poucos profissionais especialistas, esse fato fica explícito nos estudos A1 e A3.

Essa realidade evidenciada em A1 permite demonstrar que a quantidade mínima de trabalhadores para compor a equipe da ESF não supre as necessidades da população adstrita na área territorial de abrangência. Entretanto, a insatisfação de não haver médicos de várias especialidades para atender a população reforça a incompreensão desses usuários quanto aos propósitos da ESF como estratégia de organização da APS.

No entanto, de acordo com A3, ainda que se reivindique determinada especialidade, com a justificativa de que o generalista não dá conta de atender a especificidade do homem, 
faz-se necessário evitar uma visão reducionista ou fragmentalizadora da atenção primária, em que circunscreve a especificidade do usuário homem apenas na urologia.

No estudo A7, desenvolvido por Schraiber (2010), ressalta que embora os profissionais reconheçam que os homens possuem necessidades específicas, eles apontam dificuldades para atuarem junto à população masculina, justificando pela forma como eles buscam os serviços de APS, na maioria das vezes em busca de cuidados de cunho curativo. Segundo relatos dos profissionais entrevistados, os homens só se reconhecem portadores de necessidades quando percebem alguma doença instalada ou quando sentem dor.

Em A6, Couto et al. (2010) justificou a invisibilidade dos homens nos serviços de atenção primária quando observaram que os ambientes não favoreciam a presença e permanência dos homens, já que todos se apresentam como espaços demarcadamente femininos. Como exemplo, nas áreas comuns e de grande circulação, como recepção e sala de espera, há sempre muitos cartazes, produzidos pelo MS, veiculando mensagens de promoção da saúde. Temas como promoção do aleitamento materno, pré-natal, prevenção de DST e HIV/AIDS são comuns e apresentam forte conotação feminina, excetuando alguns sobre o uso correto do preservativo e sobre hanseníase.

Somado a isso, ainda em A6, nota-se o reforço da feminilização dos ambientes das unidades tanto pelos materiais de educação em saúde como pelos puramente decorativos que são produzidos internamente (pelos funcionários). Assim, embora se possa perceber relativa mudança no padrão de comunicação do MS, pela inclusão de referências de gênero, geração e raça/etnia nos materiais, tal intento ainda não alcança as equipes dos serviços em suas produções locais. Em suma, marcas pessoais influenciadas pelo imaginário de gênero são visivelmente transpostas para o ambiente público/institucional da saúde.

Além disso, o artigo A3 mostra que a organização do sistema de saúde historicamente vem sendo desenhada a partir da valorização do cuidado à saúde da mulher e da criança, tanto no meio profissional quanto no imaginário social, e, por conta disso, demarca as diferenças de abordagens de acolhimento por gênero, promovidas pelos serviços de saúde (instância micro) e as políticas de saúde (instância macro).

Em A4 um usuário da UBS ressalta que, havendo boas campanhas publicitárias voltadas aos homens, eles iriam dar mais atenção a sua própria saúde. Esse anseio vai de encontro ao que diz um dos objetivos da PNAISH, que tem a missão de ampliar, através da educação, o 
acesso dos homens às informações sobre as medidas de promoção e de prevenção contra os agravos e enfermidades que atingem a população masculina.

A atenção à saúde requer uma mudança na concepção de mundo e na forma de utilizar o conhecimento em relação às práticas de saúde, voltando o seu enfoque especialmente para a promoção da saúde. É muito mais do que uma aplicação técnica e normativa, ou seja, a promoção da saúde está relacionada à potencialização da capacidade individual e coletiva das pessoas para conduzirem suas vidas frente aos múltiplos condicionantes da saúde (SALIMENA et al., 2013).

A pesquisa desenvolvida por Fontes et al. (2011) revelou, por um lado, o déficit de conhecimento da população masculina em relação à promoção da saúde e à prevenção de agravos e, por outro, o grande desafio para implementar ações de educação que visem a romper os déficits de autocuidado desses indivíduos, bem como dos exercentes da área da saúde. Haja vista a importância da PNAISH para uma efetiva interlocução entre o ensino e os serviços de saúde.

Nesse contexto, de acordo com Silva (2013) percebe-se a necessidade de aumentar o nível de conscientização, quanto à prevenção, promoção e adesão do homem ao serviço primário de saúde, e o conhecimento da população masculina sobre os fatores de risco das doenças acometidas. E ainda, reduzir no sistema público de saúde as taxas de morbidade e mortalidade.

As pesquisas A2, A3 e A5, mostram que fatores emocionais como preconceito, medo, vergonha e machismo têm grandes impactos na negligência à saúde dos homens.

Pinheiro (2011), em A2, destaca que o câncer de próstata consiste em um dos problemas mais lembrados na discussão da saúde dos homens. No entanto, o exame para detecção precoce carrega uma gama de preconceito. Esse problema de saúde é acompanhado por uma tensão proveniente dos sentidos acionados pelo formato de um dos procedimentos utilizados na prevenção, o toque retal. Por envolver a exposição e o contato com as nádegas dos usuários homens, esse procedimento assume a conotação de ameaça à masculinidade.

Pela conotação sexual que adquire e aciona, a prevenção do câncer de próstata torna-se assunto relacionado à sexualidade masculina pelo viés da ameaça à masculinidade. Daí, o toque retal ou a simples alusão a ele serem, com frequência, acompanhados de constrangimento ou vergonha, inclusive por parte dos homens mais jovens, que estão longe de serem indicados à 
realização desse procedimento. Nessa direção, se dá a resistência ou a recusa de alguns homens a se submeterem ao exame (PINHEIRO, 2010).

Segundo os profissionais entrevistados na pesquisa A3, há uma marca cultural no aprendizado de como se cuidar, que faz com que o homem chegue ao serviço de saúde com intercorrências graves. Há no ambiente familiar uma socialização de ideias que não estimulam um comportamento masculino de autocuidado, já que ao longo da trajetória pessoal o cuidado dos homens é geralmente mediado por figuras femininas como mãe, companheira e filha.

De acordo com Gomes (2011a) em A3, esse tipo de comportamento influencia não só no estado em que esse usuário chega ao serviço de saúde, mas também na maneira como o utiliza. A explicação para esse comportamento se liga às exigências dos modelos hegemônicos de masculinidades.

Figueiredo (2011) em A5, diz que apesar disso, os profissionais de saúde não podem desconsiderar essas concepções culturais. Ao contrário, devem ficar atentos a esses pontos de vista que permeiam o senso comum, pois os mesmos, certamente, servem de argumentos para a compreensão dos processos relacionados às necessidades e cuidados de saúde da população masculina.

\section{Considerações Finais}

A análise dos artigos permitiu evidenciar que os fatores que mais contribuem para invisibilidade dos homens na atenção primária são: filas extensas; horário de funcionamento das instituições de saúde incompatível com a jornada de trabalho; poucos profissionais atuando na ESF; ausência de especialidades médicas; demora em conseguir consulta médica e exames laboratoriais; inexistência de programas voltados para a saúde masculina; vergonha; preconceito e medo.

Esses fatores aliados a ausência de cultura do autocuidado faz com que grande parte dos homens deixe de procurar uma assistência básica para procurar uma assistência avançada quando a dor já incomoda muito. Essa demora em busca de cuidados permite que as doenças se tornem mais severas causando sérias lesões ou até mesmo óbito. 
Dessa forma, podemos perceber que a responsabilidade de recrutar os homens para à APS não é tarefa exclusiva dos profissionais de saúde que trabalham na unidade, mas também dos homens, que reproduzem um pensamento mágico de que não adoecem, distanciando-se cada vez mais de práticas de promoção e prevenção. Ademais, as instâncias de saúde pouco incentivam a realização de campanhas e outras formas de disseminar informações aos homens.

Para realização desta revisão encontrou-se como limitação a dificuldade de encontrar publicações no período determinado como critério de inclusão que foi de 2009 a 2013 . Outro problema foi o uso dos descritores, tendo em vista que vários estudos eram encontrados durante a busca, no entanto durante a análise na integra os mesmos não se enquadravam na temática, o que pode ser indício de uso incorreto dos descritores por alguns autores.

É válido destacar que os profissionais de saúde podem desenvolver muitas estratégias para incentivar os homens a cuidarem de sua saúde. Dessa forma, podem se qualificar cada vez mais para melhor atender a população masculina; criar espaço para os usuários do sexo masculino e um grupo específico para discussão da Saúde do Homem; gerenciar a demanda para que não haja grandes filas, realizar visitas domiciliárias e promover uma assistência íntegra.

Medidas como estas, podem melhorar de forma significativa o fluxo da população masculina às UBS, promover a prevenção e a promoção da saúde e mudar certos pensamentos de caráter machista que impedem os homens de se cuidarem. Melhorando assim, a qualidade de vida dessa população e aumentando a expectativa de vida.

Por fim, os achados deste estudo apontam para a necessidade de realização e publicação de outras pesquisas, devido ao quantitativo reduzido de estudos atuais sobre a assistência ao homem no nível primário de atenção à saúde, visando desenvolver ações que busquem conhecer as especificidades da população masculina para melhor atuar sobre elas.

\section{Referências}

ALBANO, B. R.; BASÍLIO, M. C.; NEVES, J. B. Desafios para a inclusão dos homens nos serviços de Atenção Primária à Saúde. Revista Enfermagem Integrada, v. 3, n. 2, p. 554-563, 2010 .

ALVARENGA W. A, et al. Política de saúde do homem: perspectivas de enfermeiras para sua implementação. Rev Bras Enferm, v. 65, n. 6, p. 929-935, 2012. 
BRASIL. Ministério da Saúde, 2010. Homens de 20 a 29 anos morrem quatro vezes mais que mulheres da mesma faixa etária, diz Saúde. Disponível em: <http://www.brasil.gov.br/saude/2010/12/homens-de-20-a-29-anos-morrem-quatro-vezesmais-que-mulheres-da-mesma-faixa-etaria-diz-saude>. Acessado em 15 de Nov. 2013.

Ministério da Saúde, 2010. Problemas do coração e câncer de próstata são as doenças que mais matam os homens. Disponível em: <http://gruponoticias.jusbrasil.com.br/politica/5554164/problemas-do-coracao-e-cancer-de-prostata-sao-asdoencas-que-mais-matam-os-homens>. Acessado em: 15 de nov. 2013.

. Ministério da Saúde. Manual do Instrumento de Avaliação da Atenção Primária à Saúde. Secretaria de Atenção em Saúde, Departamento de Atenção Básica. Brasília, 2010.

Ministério da Saúde. Secretaria de Atenção à Saúde. Departamento de Ações Programáticas Estratégicas. Política Nacional de Atenção Integral à Saúde do Homem. Brasília: Ministério da Saúde, 2008.

BRITO, R. S.; SANTOS, D. L. A.; MACIEL, P. S. O. Olhar masculino acerca do atendimento na estratégia saúde da família. Rev. Rene. Fortaleza, v. 11, n. 4, p. 135-142, 2010.

COUTO, M.T. et al. O homem na atenção primária à saúde: discutindo (in) visibilidade a partir da perspectiva de gênero. Interface - Comunic., Saude, Educ., v.14, n.33, p. 257-70, 2010.

DOMENICO, E. B. L.; IDE, C. C. A. Enfermagem baseada em evidências: princípios e aplicabilidades. Rev Latino-am Enfermagem, v. 11, n. 1, p. 115-8, 2003.

DUARTE, S. J. H.; OLIVEIRA, J. R.; SOUZA, R. R. A Política Saúde do Homem e sua operacionalização na Atenção Primária à Saúde. Revista Eletrônica Gestão \& Saúde, v. 3, n. 1, p. 520-530, 2012.

FIGUEIREDO, W. S. Assistência à saúde do homem: um desafio para os serviços de atenção primária. Ciências \& Saúde Coletiva, v. 10, n. 1, p. 105-109, 2005.

FIGUEIREDO, W. S.; SCHRAIBER, L. B. Concepções de gênero de homens usuários e profissionais de saúde de serviços de atenção primária e os possíveis impactos na saúde da população masculina, São Paulo, Brasil. Ciência \& Saúde Coletiva, v.16, n. 1, p. 935-944, 2011.

FONTES, W. D. et al. Atenção à saúde do homem: interlocução entre ensino e Serviço. Acta Paul Enferm, v. 24, n. 3, p. 430-433, 2011.

GOMES, R. et al. Os homens não vêm! Ausência e/ou invisibilidade masculina na atenção primária. Ciência \& Saúde Coletiva, v. 16, n. 1, p. 983-992, 2011 a.

O atendimento à saúde de homens: estudo qualitativo em quatro estados brasileiros. Physis Revista de Saúde Coletiva, Rio de Janeiro, v. 21 n. 1, p. 113-128, 2011 b. 
GOMES, R.; NASCIMENTO, F. N.; ARAÚJO, F. C. Por que os homens buscam menos os serviços de saúde do que as mulheres? As explicações de homens com baixa escolaridade e homens com ensino superior. Cad. Saúde Pública, v. 23, n. 3, p. 565-574, 2007.

ISTITUTO BRASILEIRO DE GEOGRAFIA E ESTATÍSTICA - IBGE. Brasil: Tábua Completa de Mortalidade - 2010. Rio de Janeiro, 2011. Disponível em: http://www.ibge.gov.br/home/estatistica/populacao/tabuadevida/2010/notastecnicas. Acessado em: 13 de nov. de 2013.

Brasil: Tábua Completa de Mortalidade - 2011. Rio de Janeiro, 2012. Disponível em:ftp://ftp.ibge.gov.br/Tabuas_Completas_de_Mortalidade/Tabuas_Completas_de_Mortalid ade_2011/notastecnicas. Acessado em: 13 de nov. de 2013.

KNAUTH, D. R.; COUTO, M. T.; FIGUEIREDO, W. S. A visão dos profissionais sobre a presença e as demandas dos homens nos serviços de saúde: perspectivas para a análise da implantação da Política Nacional de Atenção Integral à Saúde do Homem. Ciência \& Saúde Coletiva, v. 17, n. 10, p. 2617-2626, 2012.

LEAL, A. F.; FIGUEIREDO, W. S.; SILVA, G. S. N. O percurso da Política Nacional de Atenção Integral à Saúde dos Homens (PNAISH), desde a sua formulação até sua implementação nos serviços públicos locais de atenção à saúde. Ciência \& Saúde Coletiva, v. 17, n. 10, p. 2607-2616, 2012.

LIMA, V. C. Ausência dos usuários homens na atenção primária: revisão integrativa. Revista Formar Interdisciplinar, v.1, n.2, p. 42-50, 2013.

LUIZAGA, C. T. M. Mortalidade Masculina no Tempo e no Espaço. Dissertação Faculdade de Saúde Pública, Universidade de São Paulo, 2010.

MACHIN, R. et al. Concepções de gênero, masculinidade e cuidados em saúde: estudo com profissionais de saúde da atenção primária. Ciência \& Saúde Coletiva, v. 16, n. 11, p. 45034512, 2011.

MARQUES, R. M.; MENDES, A. A política de incentivos do Ministério da Saúde para a atenção básica: uma ameaça à autonomia dos gestores municipais e ao princípio da integralidade? Cad. Saúde Pública, v. 18, p. 163-171, 2002.

MATUMOTO, S.; MISHIMA S. M.; PINTO, I. C. Saúde Coletiva: um desafio para a enfermagem. Cad. Saúde Pública, v 17, n. 1, p. 233-241, 2001.

MEDRADO, B. et al. Princípios, diretrizes e recomendações para uma atenção integral aos homens na saúde. Recife: Instituto PAPAI, 2009.

PINEIRO, T. F.; COUTO, M. T.; SILVA, G. S. N. Questões de sexualidade masculina na atenção primária à saúde: gênero e medicalização. Interface - Comunic., Saude, Educ., v.15, n.38, p.845-858, 2011. 
SALIMENA, A. M. et al. Saúde do homem e atenção primária: o olhar da enfermagem. Rev APS, v. 16, n. 1, p. 50-59, 2013.

SCHEUER, C.; BONFADA, S.T. Atenção à saúde do homem: a produção científica de enfermeiros na atenção básica. Revista Contexto \& Saúde, v. 7, n. 14, p. 7-12, 2008.

SCHRAIBER, L. B. et al. Necessidades de saúde e masculinidades: atenção primária no cuidado aos homens. Cad. Saúde Pública. Rio de Janeiro, v. 26, n. 5, p. 961-970, 2010.

SCHWARZI, E. et al. Política de saúde do homem. Rev Saúde Pública, v. 46, n. 1, p. 108-116, 2012.

SILVA, B. T. O. et al. Promoção e prevenção da saúde do homem. Interfaces Científicas Saúde e Ambiente, v.2, n.1, p. 95-101, 2013.

SILVA, P. A. S. et al. A saúde do homem na visão dos enfermeiros de uma unidade Básica de saúde. Esc Anna Nery (impr.), v. 16, n. 3, p. 561- 568, 2012.

SOUZA, E. C. F. et al. Acesso e acolhimento na atenção básica: uma análise da percepção dos usuários e profissionais de saúde. Cad. Saúde Pública, v. 24, n. 1, p. 100-110, 2008.

SOUZA, M. T.; SILVA, M. D.; CARVALHO, R. Revisão integrativa: o que é e como fazer. Einstein, v. 8, n. 1, p. 102-6, 2010.

URSI, E.S. Prevenção de lesões de pele no perioperatório: revisão integrativa da literatura. 2005. 130 f. [Dissertação]. Ribeirão Preto (SP): Escola de Enfermagem de Ribeirão Preto, Universidade de São Paulo, 2005.

WHITTEMORE, R.; KNAFL, K. The integrative review: updated methodoly. J Adv Nurs. v. 52, n. 5, p. 546-553, 2005.

Como citar este artigo (Formato ABNT):

COELHO, Saryse Figueredo Castro; MELO, Rosana Alves de. Assistência ao Homem na Estratégia Saúde da Família. Id on Line Rev.Mult. Psic., 2018, vol.12, n.41, p. 485-508. ISSN: 1981-1179.

Recebido: 16/06/2018

Aceito 28/06/2018 